This item was submitted to Loughborough's Research Repository by the author.

Items in Figshare are protected by copyright, with all rights reserved, unless otherwise indicated.

\title{
Culture, boundary, and identity: a comparison of practices between two online punk communities in China
}

\author{
PLEASE CITE THE PUBLISHED VERSION
}

http://dx.doi.org/10.1080/17544750.2016.1207695

\section{PUBLISHER}

(C) The Centre for Chinese Media and Comparative Communication Research, The Chinese University of Hong Kong. Published by Taylor \& Francis

\section{VERSION}

AM (Accepted Manuscript)

\section{PUBLISHER STATEMENT}

This work is made available according to the conditions of the Creative Commons Attribution-NonCommercialNoDerivatives 4.0 International (CC BY-NC-ND 4.0) licence. Full details of this licence are available at: https://creativecommons.org/licenses/by-nc-nd/4.0/

\section{LICENCE}

CC BY-NC-ND 4.0

\section{REPOSITORY RECORD}

Xiao, Jian, and James Stanyer. 2019. "Culture, Boundary, and Identity: A Comparison of Practices Between Two Online Punk Communities in China”. figshare. https://hdl.handle.net/2134/23587. 


\title{
Culture, Boundary and Identity: A Comparison of Practices Between Two Online Punk Communities in China
}

\begin{abstract}
:
This article analyzes how digital technology can shape cultural practice in Chinese online communities. By using the concepts of boundary and identity, it explores the formation of two online punk communities in China, created by those who are interested in punk music originating from the Anglo-American countries. Drawing on data from participant observation and 10 in-depth interviews, this article first reviews literature on Internet culture in China, online community, boundary and identity. It then focuses on the differing practices of the two online punk communities. A discussion is subsequently provided, of how boundaries are constructed in the online communities through exclusion enabled by the technological platform. An analysis of how the members identify themselves with online communities and form punk subculture encouraged by the boundaries of their respective communities is then presented towards the end of the article. It is through this process, that the members empower themselves in their relationships with their surrounding society.
\end{abstract}

Keywords: online community, identity, boundary, punk, practice

\section{Introduction}

China's rapid development in adopting the use of the Internet has given rise to a growth in Internet cultural phenomena. It is increasingly possible to observe online users generating and experiencing collective cultural practices along with the growth of online communities in China. The punk phenomenon, which originated from Anglo-American countries with its philosophy of promoting individual freedom and an anti-official/government stance (O'Hara, 1999), has existed in China since $1996^{1}$. After twenty years' development, Chinese punk bands with a variety of punk styles have become widely and loosely distributed across different cities around China. In recent years, punk culture has expanded onto the online world in China. Two prominent punk forums - "Punk" forum established in 2006 and "Punk is Not Dead" 2 forum established in 2009 - exist and serve as focal spaces for online users who are interested in punk music and culture. 
An online community, where members interact mainly by means of computer-mediated communications, such as asynchronous discussion forums or chat rooms (Scott \& Johnson, 2005), not only serves to gather people who are physically separated (Stone, 1991) but also enables them to commit to a set of shared values and beliefs in a web of affect-laden relationships (Etzioni \& Etzioni, 1999). This can be seen in the case of online punk communities where individuals interact with each other and create meanings through their online activities. In this article, we use the term "practice" to explore online members' "routinized ways of behavior" (Reckwitz, 2002, p.249), and look at how they systematically produce texts, symbols or technology (Johnson, 2001). Appropriating this concept, differing practices are noticed to exist between the two contrasting online communities due to the group members' respective identifications with punk. So far, discussions of Internet cultural phenomena or online communities in China fall mainly onto the specific social implications that they bring to Chinese society and culture (for instance, Cai, 2007; Gong \& Yang, 2010; Yang, Tang \& Wang, 2015; Zhang \& Mao, 2013). Though this is important, we know little about how online members form their identities, establish norms, and ultimately, sustain the culture through different practices in the Chinese social context. Moreover, the term "online" is applied here to indicate the Internet-supported space where individuals conduct their activities, while serving as an integral part in their daily lives. As the Internet penetrates our lives, the online and the offline exist in a single social realm (Yuan, 2012). Thus we further consider the impact of online communities on individuals' life worlds. To address these questions, we deploy the concepts of boundaries and identities to shed light on the studies of online communities in China, an approach hardly seen in existing literature that is relevant to the Chinese context.

We start by reviewing existing literature on Internet culture in China followed by a discussion of online communities and the concepts of boundaries and identities. We then examine the different practices in the two forums and how boundaries are constructed. Towards the end of the article the processes of identification with online communities are analyzed. 


\section{Internet Culture in China}

Scholars are seeking explanations of implicit political meanings behind online cultural activities that have emerged in China since "explicitly confrontational discourses or content constitutes only a proportionately tiny part of China's cyberculture" (Yang, Tang \& Wang, 2015, p. 198), due to the powerful online censorship operated by the Chinese government. For instance, "Kuso" culture, where online users produce online collages and parody videos, is argued to be a form of grassroots youth resistance to the authority that exists in the mainstream movie-making elite culture and in government propaganda (Cai, 2007; Gong \& Yang, 2010). Recent research into online communities has also featured the idea of grassroots resistance. For instance, Zhang and Mao (2013) regard the voluntary practice of translating inaccessible foreign content in online translation communities as "grassroots resistance to a market economy with Chinese characteristics" (p.57).

The Internet and online communities are often discussed together with another issue, that of the process of empowerment, in order to understand the nature of online political engagement in the Chinese context (Gong \& Yang, 2010; Huang, 2012; Zhang \& Mao, 2013). The Internet is regarded as "an imagined empowerment for netizens, who can, for the first time, intervene in the formation of an institutionalized narrative" (Gong \& Yang, 2010, p.6). According to Huang (2012), consumption practices, which are mediated through online participation in the Chinese online consumption communities, are no longer isolated and independent; the community member can thus be empowered to become a player equal to marketers. Zhang and Mao (2013) point out that the appropriation of materials from mass culture empowers the online fan communities to have potential political influence. In conclusion, it can be said that Internet culture in China is largely explored in terms of its power relation with Chinese political and social systems. 
The political implications can thus be considered as one focal element to understand online cultural communities in China. Nevertheless, attention should also be paid to how online community members conduct their practices assisted by digital technology. To achieve this, we explore two online punk communities in the Chinese social context. Punk philosophy, according to O'Hara (1999), is associated with "a belief formed around the anarchist principles of having no official government or rules, and valuing individual freedom and responsibility (who doesn't)"(p.71). In this article, we explore how members of the two online punk communities understand the punk principles that are deeply associated with a belief in having no constraints and appreciating individual freedom, and how they apply their understandings to their online practices. Moreover, this article is inspired by the concept of subculture for further reflecting on the cultural formation in these two forums. Here the term "subculture" refers to "culturally bounded, but not closed, networks of people who come to share the meanings of specific ideas, material objects, and practices through interaction"(Williams, 2011, p.39). Before discussing our findings, the concepts of online community, boundary and identity, which are deployed as analytical tools in this article, will be reviewed in the next two sections.

\section{Online community}

Focusing on how community members create meanings and a shared sense of "we-ness," Williams (2009) approaches online community by adopting the concept of symbolic communities defined by Lamont and Molnar. Symbolic community is conceptualized in order to understand those communities without face-to-face contact, such as what Anderson (1983) describes as, "the large- scale collectives that share common identities but minimally by networks of directly interpersonal relationships -nation, races, classes, genders, Republicans, Muslims and 'civilized' people" (p.96). Those who can be included into the same symbolic community may vary in their backgrounds but "have at their disposal common categorization systems to differentiate between insiders and outsiders and common vocabularies or symbols through which they create a shared identity" (Lamont \& Molnar, 2002, p.182). 
It is critical to find the common categories for a group of individuals in an online community in order to understand its formation and practice, as well as its created meanings and shared values. Informed by the concept of symbolic community, key aspects regarding the insider and outsider distinction, and shared identity construction, which are associated with the concepts of boundary and identity, can facilitate how the Internet shapes the practices of communities in the Chinese context in particular.

\section{Boundary and identity}

Boundaries are a useful analytical tool to explore the Internet and online communities. Shields (1996) contends that "the Internet creates a crisis of boundaries between the real and virtual, between times zones and between spaces, near and distant" (p.7). That boundaries break apart and re-form in a cyber space has become a new concern in discussing the manifestation of political struggle (Jones, 1995). In role-playing online communities, the boundaries between role and self can be blurred (Turkle, 1994).

Recent interests are related to how boundaries are constructed (Williams \& Copes, 2005) and what is constructed when boundaries engage (Tiidenberg, 2015) in online communities. The mechanism of constructing community boundaries, according to Williams (2009), highlights how the members exclude themselves from outsiders externally and how they differentiate themselves from each other internally through online interaction. Enlightened by the concept of symbolic boundaries, which can be defined as conceptual distinctions to "categorize objects, people, practices, and even time and space" (Lamont \& Molnar, 2002, p.168). Tiidenberg (2015) explores the way that cultural membership is performed in an online community by focusing on boundaries. Thus boundaries are helpful for looking at the internal stratification of an online community and its process of differentiation and exclusion from outsiders.

Conceptualizing boundaries is relevant to understand identity. According to Jenkins (1996), through a dialectic interplay of defining internal and external, individuals share a sense of group belongings in a process of internal 
identification by drawing community boundaries, leading to a recognition from outsiders for the emergence of their collective identities. According to Deaux and Martin (2003), boundaries can "encourage interaction within [a] setting and thus foster the development and exercise of identities consistent with the structure" (p.103). Specifically, Ashforth and Mael (1989) explain the salience identity plays in an organisation from two levels: the identities shared within the group are particularly important to interactions between members while the identities constructed as a group are prevalent when communicating outside the group, in other words, when conducting boundary-spanning work.

Assisted by digital technology, identities online have developed new features and maintained similarities compared to those offline. For example, expressing personal views has become the most important method of expressing identities in the virtual environment (Waskul, 2003). Serving to complement the face-toface world, the process of forming online identities is similar to how offline identifies form, and online interactions should be considered and conceptualized as part of people's daily lives (Williams \& Copes, 2005). Thus, we suggest highlighting how digital technology influences the construction of identities, which further impacts on the daily lives of community members.

In this article, we examine online punk communities, which have political aspirations and pursuits in China by deploying the concepts of boundaries and identities. We thus set out to explore three research questions:

RQ1: What are the main practices in the two contrasting online communities?

RQ2: How are boundaries constructed in online communities?

RQ3: How do the members identify with their respective online communities, and create shared identities encouraged by community boundaries?

\section{Method and Data}

Virtual ethnography was used to explore the online punk communities. This approach has been discussed as one possible method to examine cyberspace and cyberculture/subcultures (Hine, 2000; Williams \& Copes, 2005). As traditional ethnography involves observing informants, interviewing people and taking 
pictures on fieldwork, virtual ethnography needs to be conducted systematically in the online setting since the Internet itself can be regarded as a culture and a cultural artefact (Hine, 2000). It is thus crucial for researchers to enter the field and discover how community members use the new technology to conduct cultural activities (Zhang \& Mao, 2013). In 2012, several punk forums were identified using the Google search engine. The largest one was a forum called "Punk" (http://tieba.baidu.com/f?kw=punk); another smaller but active one was called “Punk is Not Dead” (http://tieba.baidu.com/f?kw=朋克不死).

The research was conducted in three phases. First, "observation ethnography" as described by Bainbridge (2000, p.57) was conducted in the way that the researchers remained unobtrusive, focusing on the existing thread topics in these two forums. In order to discover how the community members write and communicate with each other, we decided to start coding the threads and applied a grounded theory methodology (Charmaz, 2000). As this process involved immersing ourselves in the data (Mills, Bonner \& Francis, 2006), we used the data to develop coding categories and theoretical understandings. In this period, one of the authors saved textual files of the threaded posts and started to read every message produced by the members. A total number of 4593 posts from "Punk" forum and 484 posts from "Punk is Not Dead" forum were recorded and coded from the beginning of August to the end of September 2012. When coding the data, we looked at the themes of the posts through their titles and content, and used five categories to make sense of our data: idle talk, sharing of music resources, punk-themed topics, judging the forum environment, and expressing political dissent. In this process, we found that large amounts of "idle talk" (the discussion threads of which were referred to using the term "Shui", meaning "non-sense", and seemed irrelevant to punk) existed in "Punk" forum in comparison to "serious" punk topics (sharing knowledge, discussing punk values and being a punk) in "Punk Is Not Dead" forum. This led us to consider employing the concept of practice in understanding the members' behaviors and the concept of identity in understanding how the members regard themselves as punks. 
Second, following the completion of the first coding stage, participatory research (Bainbridge, 2000) on the two forums was conducted from the beginning of October to the end of December 2012. One author registered an account on both forums and participated in the latest online interactions, for instance, by commenting on the latest discussion threads, chatting with the members, and starting new threads based on the coding results. For instance, the author asked questions about how the forum members interpret their common practice of posting "idle talk" threads in "Punk" forum, whereas in "Punk is Not Dead" forum, a thread themed "discussing punk spirit" was initiated. At this stage, the new data regarding how the members attached meanings to their behavior was collected, and the strategy of keeping these meanings displayed in our theoretical outcome was continued (Charmaz, 2001). Based on the new data, we have further theoretical thoughts on the concept of boundary in understanding the conflicts among the members within the forum and the oppositions between the two forums. These guided us to the next stage of interviewing the members for deeply understanding boundary and identity construction in the two punk forums.

As a researcher and a regular participant, the author was familiarized with the forum environment and established rapport with forum members through constantly sharing and exchanging ideas. In particular, the author established contact with key participants, such as the heads of the forums or the most active users. It was at this stage that three important features of these two forums were understood: the technical resources at forum users' disposal, the sociodemographical characteristics of forum members, and the existing hierarchy.

Both forums are hosted on the same platform - the website "Baidu" - and are therefore similar in style and functionality. The main mode of communication is message threading of a particular topic, and members can reply to the topic in general or to particular respondents' answers in each thread. As forum members need to register user accounts, their participation levels are automatically tracked and change from low to high based on the time that they spend on the website and the number of messages that they post. The most active threads can 
be easily found since the front page lists discussions in a chronological order, with those threads having been posted to most recently appearing at the top of the page. Moreover, each registered forum member automatically gains a user file that records their daily forum activities such as threads that they initiate, reply to or like.

During the research period, "Punk" forum had over 8,000 users compared to over 300 users active in "Punk is Not Dead" forum. Through chatting with forum members and viewing the thread contents, it was acknowledged that both forums were dominated by young people from different areas in China, who are mostly punk fans and in their early 20s, whereas "Punk" forum also contains a certain number of older members in their late $20 \mathrm{~s}$.

Both forums were open to registration. The hierarchy in structure was manifested in the way that the forum heads had the right to sanction or ban unpopular user accounts and could choose certain posts that would always stay on the front page. Meanwhile, the author noticed that senior members usually gained more replies to their posts as a result of their intense participation over the years, and therefore gained power in influencing the junior members.

The complexity of the research process required a third phase: interviewing forum members and exploring how they articulate their practices. With written consent from the participants obtained through emails, a total of 10 active group members were interviewed with six from "Punk," three from "Punk is Not Dead" and one group member active on both forums. In particular, one interviewee was sanctioned by "Punk" forum and was thus reached directly through his online account. This was done via online messaging software during the period towards the end of December 2012 and each interview lasted around two hours. At this stage, we understood how these group members approached punk through online and offline participation.

\section{Differing practices between two online communities}


In "Punk" forum, the participants were keen on producing "idle talk" threads for socializing while in "Punk is Not Dead" forum, "sharing of music resources" was the most popular thread type. The observant and participant research stages encountered many "idle talk" threads in "Punk" forum such as:

Impossible! Sister "Loving Rain" (the account name of a member) is actually a male!!! Please tell me it is not true. (Zhuai Zhuai Baobei).

"Idle talk" serves a social function for the different group members, in this case, for familiarizing with each other. In the typically frivolous discussion under this thread, a few of the forum members wrote about their confusions about the gender of the forum member "Loving Rain". Typically, this type of "idle talk" thread was welcomed in the forum and could therefore attract many replies.

According to one key participant, "Punk" forum was established in 2006 for punk fans to interact with each other. Nevertheless, the overload of "idle talk" in the "Punk is Not Dead" forum started to dissatisfy some of the forum members as well as people who were interested in joining punk-related forums, and hence they developed an alternative, i.e. "Punk is Not Dead" forum, to concentrate on actual discussion of punk. The distinction between the two forums lies in the practice of producing different types of threads. A typical thread in "Punk is Not Dead" forum would encourage group members to share music materials or their understanding of punk philosophy (forum members discussed this with the term "punk spirit"). The coding results showed that a large number of threads were titled, for instance, "please share some nice punk music", "a comment on the classic album 'Never Mind The Bollocks' from the Sex Pistols", "sharing the document 'Punk is Not Dead'”, etc. In particular, there was a tendency to regard Western punk bands as ideal and authentic punk in the forum; it was reified both through an almost complete idolizing of them and through pejorative criticism of Chinese punk bands by the forum members.

By seeking to influence each other's listening to punk music, the forum members tackled a deeper issue than simply discussing the music style: how to approach "punk spirit". During the participant period, it was recognized that 
posts for discussing punk spirit were popular among the members. One post for example states:

Punk spirit is about rebellion. If you like or don't like something, you speak it out loud. (Dong Xiao Yang)

Through defining punk spirit, the online practice in this forum serves to form a frame of reference regarding the understanding of punk. Comparatively, the norm of "Punk" forum is shaped by large amounts of "idle talk" and therefore comes to be one of not discussing punk itself while "Punk is Not Dead" forum has established the norm of seriously talking about punk music or spirit.

Online members are the carriers of practices, which can be accordingly understood as "routinized ways of understanding, knowing how and desiring" (Reckwitz, 2002, p.250). Therefore, different practices not only serve to shape the forum norms, but can also imply different understandings and expectations that the members have for their forums. In fact, the chronology of the relationship between the two forums mentioned earlier has suggested their oppositions to each other. Although the members of "Punk" forum were rarely observed to refer to the other forum, possibly due to their greater size and influence, members of "Punk Is Not Dead" forum explicitly referred to "Punk" forum and their disagreements with its format, and asserted how their forum was different in goal and style. Through refusal to create a frivolous environment, a boundary is invoked in this process of rejection of and differentiation from the "idle talk" threads in the other forum through maintaining its own seriousness. This process of boundary construction can be found not only between online communities but also within an online community, which will be further analyzed in the next section.

\section{Boundary construction}

Possible sanctions can be executed when norm violation happens online; violating explicit norms regarding inappropriate content defined by the site can result in account suspension on SNSs (McLaughlin \& Vitak, 2011). Likewise, negative reactions to norm violation in online punk communities can result in various tactics employed to enforce group norms. In this process, a forum 
boundary is enacted and further shapes these two communities. This section will focus on the textual practices of online members in elaborating the construction of community boundaries.

During the participant research period, Mr O's case of norm violation was noticeable because of his exclusion from "Punk" forum. One author observed that a particular style of post mainly containing insults towards him kept reoccurring. For example:

Mr 0, why don't you go to be a nanny who works for a community? You are always talking about useless stuff. (Mi Shi Dao)

You are disgusting, Professor O. (Hao Xiang Bu Shi)

Through chatting with forum members, it was found that $\mathrm{Mr} O \mathrm{O}$ actively initiated punk-related posts. The criticisms from the other members - who in this case can be regarded as the norm protectors - towards $\mathrm{Mr} O \mathrm{O}$ were derived from his textual practice of commenting on punk music. Instead of appreciating his attempted contributions to the community's discussions, group members responded rudely to his practice and deemed it as "useless". Mr O was sarcastically called a "professor" or "nanny," implying his behavior of repeatedly "showing off" his supposedly meaningless knowledge. The emergence of insulting threads suggests that opposition and antagonism exist in the relation between "serious" posters and "idle talk" posters, and ultimately, between the norm follower and the violator. More importantly, the conflicts between the members have invoked a boundary through the process of rejecting the punkrelated threads in this forum.

From the interview with the head of "Punk" forum, the tension between Mr O and some of the group members became more severe over time. Mr O's intense but disturbing participation finally led the forum head to banish $\mathrm{Mr} \mathrm{O}$ by deleting his posts and sanctioning his account. Meanwhile, the threads insulting $\mathrm{Mr} \mathrm{O}$ were kept in "Punk" forum. As a consequence, one author observed that Mr O's threads were effectively censored by being blocked with no content remaining available for view, leaving behind only the insulting posts from the other forum members. 
In order to gain his interpretation of this issue, contact with $\mathrm{Mr} 0$ was initiated via private messaging (this function still worked despite the account being blocked). After interviewing him, it was found that $\mathrm{Mr} O$ attributed this exclusion to forum members' demand of establishing "fake" group identities:

I went to the "Punk" forum to fight with them. For so many years, they keep the 'good' tradition of not talking about punk... as long as I wrote posts about punk-related topics, my posts would be covered by all sorts of other bullshit. They are the losers cultivated by the Chinese system and Chinese education. They just follow each other.

In this battle with "Punk" forum, Mr 0 criticized the members for being brainwashed and believed that they lacked credibility for the establishment of punk identity, as it may expose an actual failed development of one in their offline settings.

In "Punk" forum, it was not unusual to meet new members who were suspicious of "idle talk" just as Mr O was. Similarly, it was not unusual to meet those who attempted to post unrelated topics in "Punk is Not Dead" forum. One author observed that threads such as "why is nobody discussing punk here" were occasionally initiated in "Punk" forum. Employing a strong sense of sarcasm, the senior forum members replied to those new members' complaints with statements such as "this is an academic forum". In other words, they maintained the same frivolous style to talk non-sense to avoid serious discussion of punk itself. Likewise, in "Punk is Not Dead" forum members took measures to reject "idle talk" by producing threads such as "do not start 'Shui' threads" and commented on those non-serious topics with "this is not allowed".

The last two sections show that differences between the two forums and the conflicts within each forum are mainly shaped by their threads, the forum boundary is enacted through rejecting and differentiating the textual style from that which is dominant in the other forum; it further divides the online punk community into two different groups: those who refuse to explicitly discuss punk online and those whose main discussion focus online is about punk itself. 
Through this solidification of differences between these two online punk communities, the relationship of "us" and "others" as well as "insider" versus "outsider" is established. Moreover, Mr O's story shows that a new pattern of message posting criticizing Mr O emerged in "Punk" forum despite his failure to encourage serious discussion about punk. This may be explained through Meyrowitz's (1997) account, “with every change in boundaries comes a new form of inclusion and exclusion, a new pattern of sharing and lacking of sharing of experience" (p. 62).

Moreover, language use can often make community boundaries visible in digital space (Williams \& Copes, 2005). In the case of online punk communities, the members conducted distinctive linguistic practices when communicating with each other. More specifically, as those from "Punk" forum often used impolite terms of address, such as the sarcastic title "nanny" in Mr O's case or "you stupid" on other occasions, those from the other forum were more polite by using "you" or "they" as terms of address. While the politeness can go unnoticed, the ironic rudeness is visible because of its deliberation (Kasper, 1990). In this case, the rudeness in "Punk" forum is conspicuous in comparison to the politeness in the other forum, since the linguistic practice from the latter seems normal despite being conducted for the purpose of being more polite. In terms of style, the members in "Punk" forum were less careful in organizing their words and tended to be spontaneous while the members in the other forum were more careful with length and content related to punk-related knowledge. Thus, the former less careful style can possibly be considered as a more casual style as opposed to the latter, a more formal one (Major, 1992). Language use facilitates the construction of the community boundaries between producing "idle talk" threads and "thoughtful" punk-related threads, hence further functioning in the identity making in the two forums.

With boundaries being constructed and negotiated, these two forums can grow into music subcultural spaces that are, according to Williams (2011), "culturally bounded but not closed" (p.39). To further understand the process of cultural formation, another research question need to be explored: how do the community members in the two online punk forums establish their identities, 
either as a punk or a forum member encouraged by respective community boundaries?

\section{Building a "we" network and creating shared identities}

In this section, we look at the performance of membership in online communities, focusing on the process of internal identification articulated and experienced by the members who are encouraged by online community boundaries; how the members express their identities externally will also be explained. It is noted that this process is shaped by how they identify with the notion of punk with respect to its values of behaving without rules, openly expressing political dissent and refusing to follow the mainstream in the virtual environment. In this section, we will also explore how the "we" identity is constituted through linguistic practice in the forums.

Internally, the members build up a sense of group belonging through interpersonal familiarization and identification with group norms. According to the participant Miss F from "Punk" forum, the "we" network was formed in this process,

We are connected because of punk and we talk about a lot of interesting stuff and things happening around us without stopping. The forum is free, intimate, disordered and casual.

By sharing and interacting with other forum members, Miss F established meaningful relationships. In this sense, the "idle talk" in "Punk" forum is both a method of not chatting about punk and a form of social interaction between members.

The participant stage encountered another thread with the initial post writing "everyone in 'Punk' forum has received 'advanced' education"; other individual members replied with the same post "we received 'advanced' education here" respectively. As collective identity refers to "alignment between people who express and enact themselves as members of a group" (Witteborn, 2007, p.559), this example has shown that members used the pronoun "we" to express themselves as a group member of "Punk" forum. While the "we" identity stresses the similarities around which the members coalesce (Cerulo, 1997), the "we-ness" 
in this case is particularly reflected in the process that the members use the same words and synaptic patterns, demonstrating their mutual understandings of the group (Johnstone \& Bean, 1997).

Moreover, producing "idle talk" threads is interpreted as a means for forum members to identify with the notion of punk and to establish their punk identity. In the words of Mr V, "when members meet something disturbing or annoying, they would start to complain like a punk does. Afterwards, they started to not chat about anything to do with punk on purpose". Instead of chatting about punk explicitly, it was observed that group members occasionally produced threads expressing political dissent, which is in line with the anti-government aspect of punk philosophy (O'Hara, 1999), for instance:

British want to rebel and they want socialism. We have socialism... why do we still want to rebel? The practical solution is to drag China back to the road of socialism from the road of materialism. (PU dan NK)

The above post criticizes Chinese socialism and encourages rebellion, a behavior that could be regarded as an expression of the punk ideals the group members pursue. While this member questions the Chinese social system, another member followed the post and commented on the fake socialism, based on the well-known phrase "a socialist country with Chinese characteristics" coined by the previous Chinese leader Deng Xiaoping.

As expression of political dissent online will potentially be censored, this pressure results in the forum members' deployment of tactics to combat censorship. During the participant period, it was observed that this style of post was popular and usually gained many replies, for instance:

Why does China have to be harmonious? [with "harmonious" written as "he na ge xie," by inserting "na ge" between the two components of "he xie," the Chinese word for harmonious]. (Li Ze Rui)

This post aimed to question the official narrative of societal value, a harmonious society. The tactic used to avoid censorship is a common one. "He xie," which means "harmonious," is a politically sensitive word since it is from 
the phrase "harmonious society" created by Chinese leaders. The member used a word "na ge" (that is) so that the post would not be detected by automatic censorship software. Expressing political dissent becomes a means to identify with the community and other group members. Ultimately, the production of these threads is a process of resisting online control and intervening with official narratives.

Externally, forum members interact with outsiders using a particular group identity, in this case, a punk identity. In interviews with us, where we can serve as the outsiders in this case, the participant Mr G from "Punk" forum explicitly used the term "punk" to identify himself and other forum members and associated the forum style with his interpretation of punk philosophy.

Punk is free. That's why "Punk" forum is formed in this free-style way. There are no rules here. Those who are obsessed with or inspired by punk have their independent mindset and inner world. It is stupid to restrict the act of punk.

The formation of "Punk" forum was intended as a process of internalizing the punk value of pursuing freedom, as interpreted by forum members; the aspiration of "being independent", which is regarded as being integral to punk identity, justifies the uncontrolled actions of forum members. By seeking explanations from punk philosophy, Mr G not only identified himself with "Punk" forum members but also attempted to make us recognize a collective punk identity - behaving without rules and restrictions.

Moreover, collective cultural identities emerge through communicating with outsiders and through consensus of an individual member's self-identification. We use the term "cultural" to further highlight how the members seek and share a sense of belonging to the subcultural network built upon specific ideas and beliefs formed through interaction and sharing (Williams, 2011). To be specific, when one author posted a thread entitled "tell me (a researcher from the university) the reasons for not talking about punk," one reply simply stated, "No need to chat about punk between punks" (RockNro), which was agreed with by a number of other forum members. In this sense, some of the forum members 
established a collective punk identity by calling themselves punks. One approach to understanding the process of building a punk identity in "Punk" forum can be associated with the way that Chinese punks are defined: they tend to implicitly criticize the government and wider society through talking non-sense (Kuking, 2014).

Comparatively, "Punk is Not Dead" forum takes the opposite approach to punk culture. Through talking about punk seriously, forum members familiarize themselves with this particular style of music and its culture. It is also noted in this forum that the members urge each other to emphasize their punk identity in the process of internal identification. During the participant period, it was observed that one thread particularly emphasized the necessity of being thoughtful as being a member of the punk group.

Being thoughtful needs time and patience... don't make others feel that the punk group is full of people who have no thoughts and insights. (Lian $\mathrm{V} Y \mathrm{Yu}$ )

The above post implies that having thoughtful discussion could potentially shape how outsiders view punks. More importantly, this advocating facilitated the formation of a collective punk image and identity, that of thoughtful punks, by stressing the demand of outsider's recognition of "Punk is Not Dead" forum. In the process of achieving a "we" network, forum members also identify their political aspirations with the notion of punk. The coding period brought us back to one message posted by the founder of "Punk is Not Dead" forum:

We accept the education and the thinking from this Celestial Empire. We follow the mainstream to go to school. Like anyone else, we go to university and think about life, painfully without any answer. The label of "not dead" for this forum has now become the biggest sarcasm. I almost feel "why bother in the first place". (Punker_hunter)

This criticism of the mainstream is accompanied with a reflection on identities. Reading as an outpouring of despair, the writing pointed out failure in both opposing the mainstream in reality and creating this virtual space as a solution to resist authoritarian control. The authoritative power possessed by the Chinese government is implied in this post through replacing "China" with the term "Celestial Empire". Thus, the idea of "we" as a group that attempts to be 
different from the mainstream is constructed through stressing the mutual failure.

The construction of boundaries has created subcultural spaces where a growing group of members can interact with each other and produce meanings through the established networks. The creation of punk identity is further shaped by the digital technology. In the virtual environment, community members tend to rely on textual practices to form frames of references for guidance and to construct their punk identities. Through strategically writing posts criticizing the Chinese government, the forum members circumvent online censorship and achieve a degree of free expression.

\section{Self-identification and individual empowerment through online and offline participation}

The above sections have examined the online practices in the respective punk forums, which are shaped by strong norms and cultural identification. In this section, we focus on how the forum members use frames of reference formed in online punk forums to cope with some aspects of their offline daily lives. Centred on responding to peer pressure and mainstream culture, some forum members make social comparisons and emphasize their uniqueness by differentiating themselves from the offline group by identifying with the online community.

Miss $\mathrm{W}$ is an active member in "Punk" forum. Regarding online and offline punk participation, she reflected on her individual experience in the interview:

I learned from "Punk" forum a lot. Punk is about being true to yourself. I don't think that punk is simply about music. It is more to do with attitude and belief. I neither listen to those so-called punk songs nor go to live shows. Those are fake things, including having Mohawks. People around me are multi-faced and compete with each other for power or money. I despise them. I am like a child and unable to learn those "skills". I want to find something real.

As discussed above, "Punk" forum does not encourage actual discussion about punk but sticks to its rule of free expression without constraints (this despite the 
forum norms clearly enacting a form of constraint on the expression of its members). This frame of reference has impacted Miss $\mathrm{W}$ and led her to interpret punk as an attitude rather than a type of music. Through identifying with "Punk" forum, Miss W emphasized the attitude of "being true," resulting in her refusing to involve herself in other punk activities related to clothing or performance. This rejection is similar to the textual practice of avoiding chatting about punk online. More importantly, it is the punk attitude that guides her to resist peer pressure and to refuse to accept mainstream values. In the process of rejection, she constructed her unique and different personal identity.

Serving as a frame of reference, punk spirit, which was discussed in "Punk is Not Dead" forum, also served the role of guiding another participant, Mr Y. He said in his interview:

I get punk resources from here. Punk spirit has influenced me a lot. One important thing is that I have learned not to compromise. If I had not been influenced, maybe I would have become a teacher after graduation. But now I have gone to music school and learned to play the guitar. I wouldn't do that if I had no idea of punk.

In Mr Y's case, he had to face pressure from his parents who supported the idea of conforming to the mainstream, i.e. becoming a teacher, and opposed his non-mainstream route, i.e. choosing a musical life. Therefore, Mr Y's choice of the latter constituted a resistance to his parents and mainstream values.

The online and the offline both serve as "the foundation of emerging cultural patterns" (Yuan, 2012, p.676) that refer to patterns of "shared meanings evolving in the course of social life" (Gotved, 2006, p.470). The members from both forums continue their offline participation centered on punk values rather than physically attending punk-related activities. In Mr Y's case, the prioritization of acquiring professional music skills through formal musical education has particularly shown a contrast to the traditional punk musical practice, which is often related to amateur music-making (Green, 2002). While the forum members gained more life possibilities, their interpretations of attributing this process to punk blurred the distinction in their lives between online and offline, and the 
arising shared meanings further enabled them to maintain their distance and struggles to their surrounding society.

From the above two sections, we can see examples of how political engagement can potentially be embedded in everyday cultural practice (Yang, Tang \& Wang, 2015). Online practices in punk communities reveal political struggle between freedom of expression and censorship in the Chinese social context; offline we hear of displays of forum members' conformity to subcultural norms and their differentiation from "square society" (Williams, 2011, p.8). Through these practices, online members empower themselves to cope with the broader socio-political environment and their daily lives.

\section{Discussion}

$R Q 1$ : What are the main practices in the two contrasting online communities?

Members in the two online forums mainly use textual practices, such as creating discussion threads and commenting on them. While the dominant norm of "Punk" forum is to not discuss punk itself and is shaped by large amounts of "idle talk", "Punk is Not Dead" forum is focused on purposely creating threads related to sharing punk music and discussing punk philosophy. With "Punk" forum rejecting serious discussion about punk, and "Punk is Not Dead" forum refusing to produce "Shui" threads and reminding its forum members not produce such threads, the two forums effectively exist in opposition to each other.

RQ2: How are boundaries constructed in online communities?

Boundaries emerge in the process of rejecting intervention from outsiders and new members to the established norms, and solidifying the differences between insiders and outsiders. In particular, members exclude norm violators and maintain their boundaries through ignoring and criticizing them, deleting their posts, and ultimately sanctioning their participation. This process is associated with a construction of "we" as those who have achieved insiders' status, and "others" as outsiders who are to be excluded. Boundaries may change 
with the interplay of inclusion and exclusion as new patterns of textual practices emerge that can broaden the boundaries in online communities. For instance, in order to maintain boundaries, the members in "Punk" forum write message posts to insult a norm violator, whose account is later blocked by the forum head. Meanwhile, a new pattern of producing threads to insult the violator occurs in the forum.

Exclusion of outsiders is also a way of boundary making in embodied space (Low, 2003; Munn, 1996). As embodied space refers to "the location where human experience and consciousness take on material and spatial form" (Low, 2003, p.10), excluded regions for outsiders can be regarded as "a space of deletions or of delimitations constraining one person's presence at particular locales" (Munn, 1996, p.448). In this scenario, the boundary is not abstract but articulated in the contestation and reconstruction of spaces (Gallaher, 1997). In this aspect digital space can be seen to be similar to embodied space.

Moreover, language can facilitate construction of community boundaries. This point has figured in previous work. For instance, scholars use the concept of speech community to explore a group of speakers with shared norms (Labov, 1972) and the quality of interactions among members (Gumperz, 1971). The community boundaries emerge when group members share the belief of their own language that is distinctive to the language of outgroups (Preston, 1989). Moreover, as language use together with communicative outcomes is integral to group identity (Goldman, Giles \& Hogg, 2014), a clearer elaboration highlights that language facilitates the process of the internal and external boundary making, further functioning in the identity construction (Lauring, 2008). While our research shares a similar viewpoint, we suggest adopting ethnographic methods to explore the meanings of language use, and not assuming that language differences directly determine the construction of boundaries and identities. As linguistic practice functions in producing them, it is not the decisive factor (Bucholtz, 1999). Thus future study is encouraged to combine a description of linguistic practice with an exploration of its social meanings. 
$R Q 3:$ How do the members identify with their respective online communities, and create shared identities encouraged by community boundaries?

To build a "we" network, members familiarize with each other and follow the forum norms in online communities. In online punk communities, this process is particularly associated with how the members identify with the notion of punk and therefore create punk identities. The process of internal identification in "Punk" forum can be seen from the norm of not chatting about punk, but producing "idle talk" and expressing political dissent, in other words, to practice doing punk. In communicating with outsiders or new members, the forum members use punk identities to emphasize their attitudes towards how to approach punk. Comparatively, the members in "Punk is Not Dead" forum stress their punk identities when communicating with people from the same group. The feature of being thoughtful and independent as a punk is identified through communicating with outsiders.

The notion of punk has become a source for the forum members to respond to their surrounding situations and general society. The practice of identifying with punk serves to empower forum members, who are guided by the frames of reference derived from their respective online communities, to seek individual freedom and expression, break the established rules and restrictions, and to not follow the mainstream in the Chinese social context that encourages conformity and is shaped by tight control from the government. This can be further embodied in the forum members who urge others to differentiate themselves from their peers and the mainstream values by identifying with punk and online punk communities.

Appropriating the concept of subculture (Williams, 2011), this article further characterizes the members from the two online forums as subcultural groups that are culturally bounded and shaped by shared interests and constant interactions. For those members, the Internet is the main source for their subcultural participation. Shaped by punk values, online members conduct their 
practices in a distinctive way based on communication, in contrast to the face-toface punk practices related to performance or clothing. Reflecting on the notion of subculture, this research has taken a different stance to that of previous studies, such as Hebdige's (1979) theorizing punk subculture as symbolic resistance through style, or Bennett's (1999) argument, using neo-tribalism as a theoretical concept to emphasize individual choice of style. By looking at an Internet subcultural phenomenon, this article provides a collective understanding of the new forms of subcultural participation related to communication transmitted through a network where the members can share materials and ideas, and interact with each other (Blackman, 2014; Williams, 2011). To further expand the research scope, exploring subcultures that develop in the virtual environment should be considered as an important direction for future subcultural studies.

\section{Conclusion}

In this article, we compared two online communities centred on punk subculture and asked three research questions to explore how the Internet shapes cultural practice, that being patterned activities organized around community values and norms (Nasir \& Saxe, 2003). More specifically, serving as an electronic network, the Internet is characterized by its linking people and information through digital devices (DiMaggio, Hargittai, Neuman, \& Robinson, 2001). Thus the Internet with its own characteristics provides the group members with opportunities to create distinctive standards of form in organizing activities, based on their beliefs of how a culturally informed online community should be. In this article, we demonstrated that this process is manifested in the differing textual and linguistic practices conducted online by the group members, and the identity making constituted in online communities, further strengthened by the construction of boundaries enabled by the technology. Regarding the textual practice, the "Punk" forum prefers to produce "idle talk" threads in contrast to the more "serious" discussions in the "Punk Is Not Dead" forum. In the aspect of boundary construction, the forums maintain their boundaries through rejecting and excluding outsiders, a process facilitated by the forum technology, which allows the forum head(s) to sanction unwanted users. In terms of identity 
making, the members conduct linguistic practices to internally identify with their forums and have externally established their identities as "free" punks without rules, or as "serious" punks.

The Internet has facilitated online users to get involved in distinctive subcultural participation that is free from the conditions required offline, such as having a close geographical network or deep commitment to the music scene. Moreover, digital technology has presented new opportunities for Chinese netizens to practice individual and collective freedom, as well as behaving without (or in opposition to) rules as imposed by the government or those applied in the mainstream through sustaining music-based subcultures online. In this process, they empower themselves in creating new types of social interaction and reshaping their relationships with the surrounding society through textual practices or distinctive offline participation.

This research enriches the current studies of online communities in China by adopting the concepts of boundaries and identities for exploration. It offers a new perspective to understanding the subtlety of the online practices and collective activities shaped by the Internet, as well as the interweaving relationship among different groups of individuals identifying with a specific culture, and the political struggle between them and their surrounding society. More research is encouraged to carefully examine the cultural activities conducted in alternative communities that pursue political aspirations.

\section{Author's Note}

The participants' names were not provided in this study to protect their identities.

\section{Notes}

${ }^{1}$ In 1996, a group of Beijing musicians first heard Western underground music, from bands such as EAST BAY, CHICAGO, or DC PUNK. Later these musicians formed the first Chinese punk band: UNDERBABY (O'Dell, 2011). 
2 The naming of the website "Punk Is Not Dead" is after the landmark Scottish band, THE EXPLOITED (1981) LP Punks Not Dead(sic) LP. Secret Records. In response to CRASS (1978) proclamation that "Punk is Dead" on The Feeding of the Five Thousand 12" Small Wonder Records.

\section{Reference:}

Anderson, B.R. (1983). Imagined communities: Reflections on the origin and spread of nationalism. London: Verso.

Ashforth, B.E., \& Mael, F.A. (1989). Social identity theory and the organization. Academy of Management Review, 14, 20-39.

Bainbridge, W.S. (2000). Religious ethnography on the World Wide Web. Religion and the Social Order: Religion on the Internet, 8,55-80.

Bennett, A. (1999). Subcultures or neo-tribes? Rethinking the relationship between youth, style and musical taste. Sociology, 33(3), 599-617.

Blackman, S. (2014). Subculture theory: An historical and contemporary assessment of the concept for understanding deviance. Deviant Behavior, 35(6), 496-512.

Bucholtz, M. (1999). "Why be normal?" Language and identity practices in a community of nerd girls. Language in Society, 28(2), 203-223.

Cai, Q. (2007). Review on the Internet Kuso culture. International Journalism, 1, 57-60, (In Chinese).

Cerulo, K.A. (1997). Identity construction: New issues, new directions. Annual Review Sociology , 23(1), 385-409.

Charmaz, K. (2000). Grounded theory: Objectivist and constructivist methods. In N. K. Denzin \& Y. S. Lincoln (Eds.), The handbook of qualitative research (pp. 509535). Thousand Oaks, CA: Sage.

- (2001). Qualitative interviewing and grounded theory analysis. In J. Gubrium \& J. Holstein (Eds.), Handbook of interview research: Context and method (pp. 675-694). Thousand Oaks, CA: Sage.

Deaux, K., \& Martin, D.(2003). Interpersonal networks and social categories: Specifying levels of context in identity processes. Social Psychology Quarterly, 66, 101-17.

DiMaggio, P., Hargittai, E., Neuman, W.R. \& Robinson, J.P. (2001). Social implications of the Internet. Annual Review Sociology, 27, 307-336.

Etzioni, A. \& Etzioni, O. (1999). Face-to-face and computer-mediated 
communities, a comparative analysis. The Information Society: An International Journal, 15 (4), 241-248.

Gallaher, C. (1997). Identity politics and the religious right: Hiding hate in the landscape. Antipode, 29 (3), 256-277.

Goldman, L., Giles, H. \& Hogg, M.A. (2014). Going to extremes: Social identity and communication processes associated with gang membership. Group Processes \& Intergroup Relations, 17(6), 813-832.

Gong, H., \& Yang, X. (2010). Digitized parody: The politics of egao in contemporary China. China Information, 24, 3-26.

Gotved, S. (2006). Time and space in cyber social reality. New Media \& Society, 8 (3),467-486.

Green, L. (2002). How popular musicians learn: A way ahead for music education. London:Routledge.

Gumperz, J.J. (1971). Language in social groups. Stanford: Stanford University Press.

Hebdige, D. (1979). Subculture: The meaning of style, London: Methuen.

Hine, C. (2000). Virtual ethnography, London: SAGE.

Huang, X.K. (2012). Lifestyles in virtual communities: Collaborative consumption and interaction. Chinese Journal of Communication, 5(1), 109-127.

Jenkins, R. (1996). Social identity. London: Routledge.

Johnson, C.M. (2001). A survey of current research on online communities of practice. The Internet and Higher Education, 4, 45-60.

Johnstone, B. \& Bean, J.M. (1997). Self-expression and linguistic variation. Language in Society, 26(2), 221-246.

Jones, S.G. (1995). Cyber society: Computer-mediated communication and community. California: Sage.

Kasper, G. (1990). Linguistic politeness: Current research issue. Journal of Pragmatics, 14(2), 193-218.

Kuking.(2014). Chinese Punk. Retrieved from

http://baike.baidu.com/view/1152078.htm, (In Chinese).

Labov, W. (1972). Sociolinguistic patterns. Philadelphia: University of Pennsylvania Press. 
Lamont, M. \& Molnar, V. (2002). The study of boundaries in the social sciences. Annual Review of Sociology, 28, 167-195.

Lauring, J. (2008). Rethinking social identity in International encounters: Language use as a negotiated object for identity making. International Journal of Cross Cultural Management, 8(3), 343-361.

Low, S.M. (2003). Embodied space(s): Anthropological theories of body, space, and culture. Space \& Culture, 6(1), 9-18.

Major, R.C. (1992). Losing English as a first language. The Modern Language Journal, 76(2), 190-208.

McLaughlin, C. \& Vitak, J. (2011). Norm evolution and violation on Facebook. New Media \& Society, 14(2), 299-315.

Meyrowitz, J. (1997). Shifting worlds of strangers: Medium theory and changes in "them" verus "us". Sociological Inquiry, 67(1), 59-71.

Mills, J., Bonner, A., \& Francis, K. (2006). The development of constructivist grounded theory. International Journal of Qualitative Methods, 5(1), 25-35.

Munn, N.D. (1996). Excluded spaces: The figure in the Australian aboriginal landscape. Critical Inquiry, 22(3), 446-465.

Nasir, N.S. \& Saxe, G.B. (2003). Ethnic and academic Identities: A cultural practice perspective on emerging tensions and their management in the lives of minority students. Educational Researcher, 32(5), 14-18.

O'Dell, D. (2011). Inseparable: The memoirs of an American and the story of Chinese Punk Rock. Lulu.com.

O'Hara, C. (1999). The philosophy of punk: More thank noise!! Oakland, CA: AK Press.

Preston, D.R. (1989). Perceptual dialectology: Nonlinguists' views of areal linguistics. Dordrecht: Foris.

Reckwitz, A. (2002). Toward a theory of social practices: A development in culturalist theorizing. European Journal of Social Theory, 5(2), 243-263.

Scott, J.K. \& Johnson, T.G. (2005). Bowling alone but online together: Social capital in E-Communities. Journal of the Community Development Society, 36(1), 1-18.

Shields, R. (1996). Introduction: Virtual spaces, real histories and living bodies. In R. Shields. (Ed.), Cultures of Internet: Virtual spaces, real histories, living bodies (pp. 1-10). London:Sage. 
Stone, A.R. (1991). Will the real body please stand up? Boundary stories about virtual culture. In M. Benedikt. (Ed.), Cyberspace: First steps (pp.81-113). Cambridge, MA: MIT Press.

Tiidenberg, K. (2015). Boundaries and conflict in a NSFW community on tumblr: The meanings and uses of selfies. New Media \& Society. Advance online publication, doi: 1461444814567984 .

Turkle, S. (1994). Constructions and reconstructions of self in virtual reality: Playing in the MUDs. Mind, Culture, and Activity, 1(3), 158-167.

Waskul, D.D. (2003). Self-games and body-play: Personhood in online chat and cybersex. New York: Lang.

Williams, J.P.(2009). Community, frame of reference, and boundary: Three sociological concepts and their relevance for virtual worlds research. Qualitative Sociology Review, V(2), 3-16.

- (2011). Subcultural theory: Traditions and concepts. Cambridge: Polity Press.

Williams, J.P. \& Copes, H. (2005). "How edge are you?" Constructing authentic identities and subcultural boundaries in a straightedge Internet forum. Symbolic Interaction, 28(1), 67-89.

Witteborn, S. (2007). The situated expression of Arab collective identities in the United States. Journal of Communication, 57(3), 556-575.

Yang, P., Tang, L. \& Wang, X. (2015). Diaosi as infrapolitics: Scatological tropes, identity-making and cultural intimacy on China's Internet. Media, Culture \& Society, 37(2), 197-214.

Yuan, E.J. (2012). A culturalist critique of "online community" in new media studies. New Media \& Society, 15(5), 665-679.

Zhang, W.Y. \& Mao, C.T. (2013). Fan activism sustained and challenged: Participatory culture in Chinese online translation communities. Chinese Journal of Communication, 6(1), 45-61. 